\title{
COMPARATIVE ANALYSIS OF THE RESILIENCE AND VULNERABILITY OF THE RAILWAY INFRASTRUCTURE
}

\section{Katarina Hoterova \\ University of Zilina, Faculty of Security Engineering, Zilina, Slovak Republic}

CMESTE

JEL Category: R41, R42

\begin{abstract}
At present, society is increasingly dependent on certain technologies, services, systems. The failure of such elements would have an impact on the functioning of the state and the very lives of the population. Such elements may be marked as critical if they meet the criteria set. The elements are assessed based on the sectoral and cross-cutting criteria of the country. The current threat is terrorism, which may jeopardize the functioning of critical infrastructure elements. It is, therefore, necessary to pay attention to their security. Security is closely related to concepts such as resilience and vulnerability. In some studies, these two terms are considered identical. The authors of this article consider these two terms as related. The article aims to analyze the approaches to these two concepts and to conclude what the two concepts are related to each other.
\end{abstract}

Keywords: resilience, vulnerability, risks, assessment, railway infrastructure

\section{INTRODUCTION}

State transport infrastructure is one of the important conditions for the development of society. Investors and citizens are very sensitive about the availability and quality of transport infrastructure if they are to move to a new space. (Dvorak, Sventkova, Rehak, \& Cekerevac, 2017) To secure the functions of the state, part of the transport infrastructure in the Slovak Republic is included in the network of selected roads from the perspective of the state defense. (Dvorak, Leitner, \& Rehak 2019) Another part of the transport network is part of the Trans-European Transport Network. Another part of the transport network is

Address of the corresponding author: Katarina Hoterova

邫katarina.hoterova@fbi.uniza.sk part of the critical infrastructure sectors. In general, critical infrastructure is essential to ensure the basic operation of selected areas of the state. (Rehak, Hromada, \& Novotny 2016) As part of the critical infrastructure protection research, researchers are looking at resilience and vulnerability. The critical infrastructure boards include those objects that meet at least one crosssectional and sectoral criterion. (Act 45) These criteria are determined by the State in which the element is located. However, these criteria are largely based on superordinate legislation, such as European directives. (Hoterova, Dvorak, \& Blaho 2019; Dvorak, Luskova, Cekerevac 2014) To ensure the functionality of these elements it is necessary to ensure their safety. The resilience or vulnerability assessment shall help the operators of critical infrastructure elements to take action to enhance the element's security. (Hoterova, 2019, Sousek, 2013) The article aims to analyze the 
different approaches to the concepts of resilience and vulnerability. There are discussions as to whether these two terms can be considered identical.

\section{ANALYSIS OF APPROACHES TO THE CONCEPTS OF RESILIENCE AND VULNERABILITY}

One of the many topics discussed is resilience to vulnerability. Discussions about whether the two concepts are so similar that they can be considered as identical. There are as many authors of the definitions as there are different opinions. These two terms are used in various fields of investigation. This chapter of the article is devoted to the analysis of the approaches of individual authors to both terms. The key point is that the authors use these terms in the technical field, in the assessment of the railway infrastructure.

\subsection{The resilience}

The term resilience is generally understood as the ability of a system to prepare, resist, and adapt to adverse effects. The measurement and analysis of resilience itself is a multifunctional activity. It depends on the uniqueness of the system under assessment. Hollnagel presents four basic points of resilience analysis:

- know what to do,

- know what to look for,

- know what to expect,

- $\quad$ know what happened. (Hollnagel 2011)

The first point, knowing what to do, is the ability to know the real disturbances and be able to respond to them or adapt to existing conditions. The second point, knowing what to look for, is the ability to identify critical factors of the internal and external environment through monitoring that can detect existing threats. The third point, knowing what to expect, means being able to address potential future threats, anticipating opportunities for change, identifying sources of potential threats. The last point, knowing what happened is a critical point in assessing resilience, is the ability to take lessons in the light of successes or failures. (Hollnagel 2011)

Based on the results of the Nordress - Nordic Center of Excellence on Resilience and Societal
Security, it can be argued that resilience and security are made up of four pillars - society, institutions, individuals, and the infrastructure itself, see Figure 1. Each of these pillars should be in good condition and cooperate smoothly with the other elements to maintain durability and security.

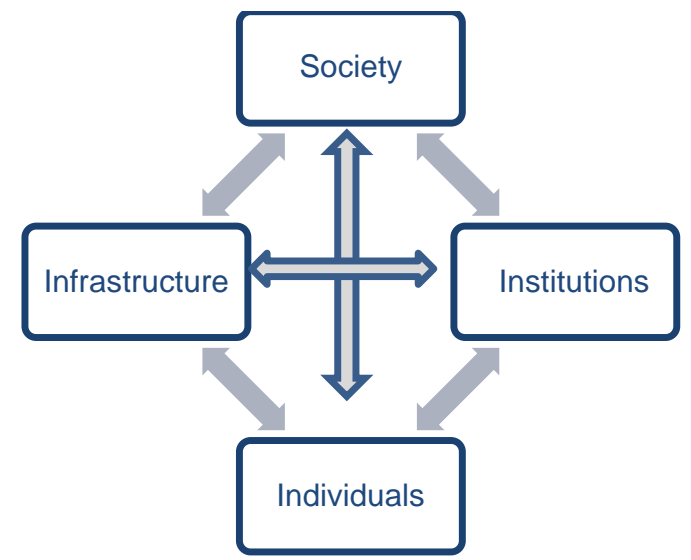

Figure 1 Relationships between the four pillars of resilience

Another approach to resilience analysis proposed by Linkov et al. (2013), The principle of the analysis is to quantify the resilience assessment, which is based on similar system capabilities that can be summarized in the following four steps:

plan / prepare,

absorb,

recover,

adapt.

To apply this approach, managers need to plan and prepare the system to deal with an adverse event while maintaining the system's most important functions. The system thus prepared can better absorb the adverse effects, to recover from the effects of the adverse event, and to adapt more flexibly to the new conditions. Linkov then analyzed these four steps in four areas of the subconscious to create a matrix of resilience evaluation. The four areas are:

physical area,

information area,

cognitive region,

organizational / social area (Linkov, 2013).

Resilience can also be perceived from the perspective of how to deal with the negative impact of an undesirable phenomenon. These can be:

- hard resilience - when the direct force of structures or institutions under pressure is 
acting, such as increasing resilience through specific reinforcement measures to reduce the likelihood of system collapse,

- soft resilience - the ability of the system to absorb and recover from the adverse effect of an adverse event, i.e. without significant changes in the functions or organization of the structure, which depend on the flexibility and adaptive capacity of the system. (Moench, 2009)

In the approach published by Rehak, resilience is understood as the internal readiness of critical infrastructure subsystems against negative threats, or the ability to ensure and maintain their basic functions in the event of a negative event of external or internal nature.

The research of the assessment of the resilience of the subsystem in critical infrastructure was devoted to the security research project of the Czech Republic called RESILIENCE2015, within which the CIERA certified methodology was developed. (Rehak et al, 2018).

Understanding and unambiguous definitions are key in assessing and strengthening resilience. Resilience is a cyclical process that involves continuous improvement in the prevention, absorption, recovery, and adaptability of the system, see.

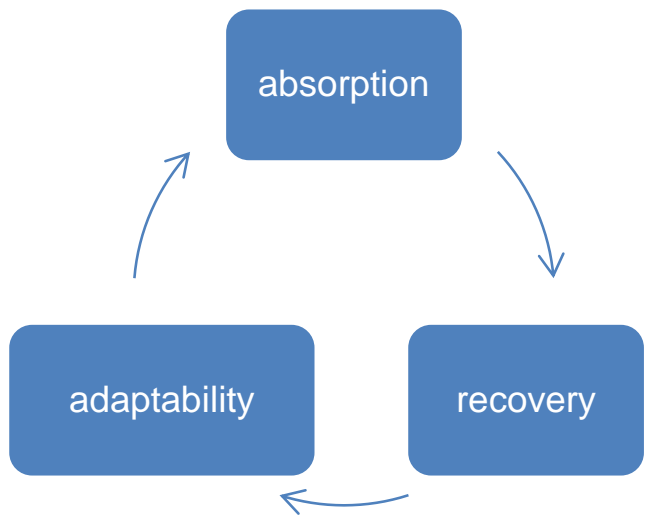

Figure 2 Cyclic resilience process Source: (CIERA, 2018)

Another important contribution of the RESILIENCE project in the field of critical infrastructure resilience research is the creation and testing of a critical infrastructure resilience assessment algorithm. Its graphical representation is shown in Figure 3.

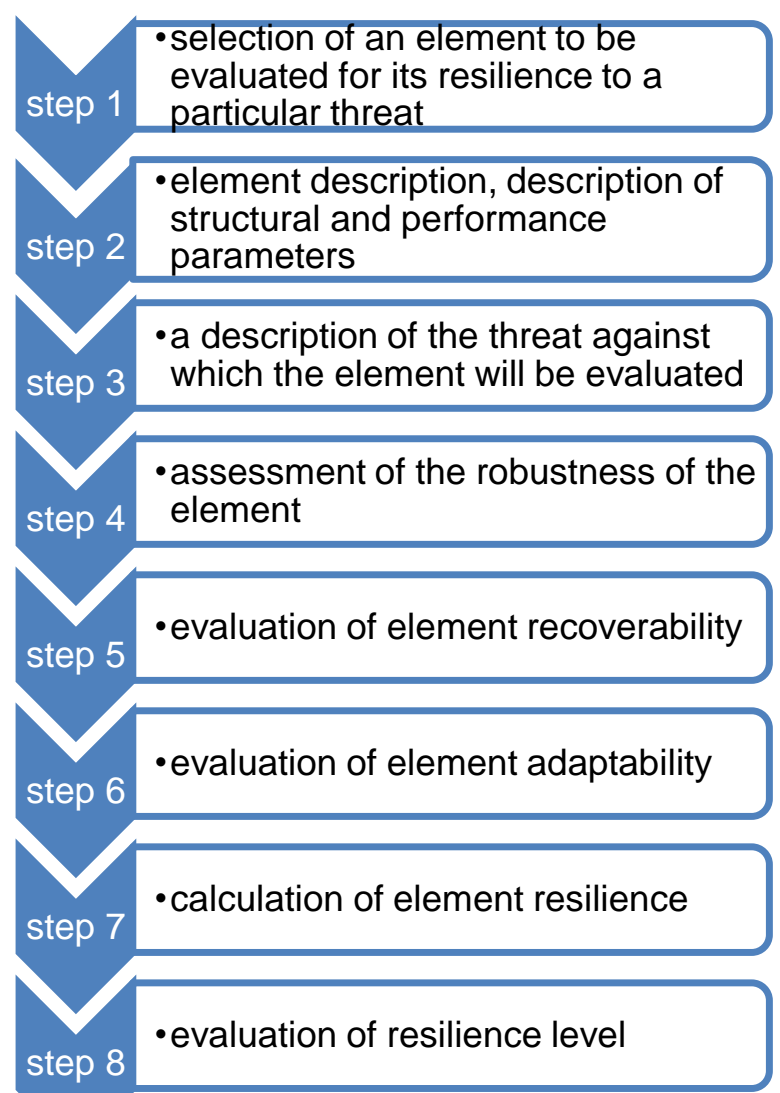

Figure 3 Resilience Rating Algorithm Source: (CIERA, 2018)

\subsection{The vulnerability}

Vulnerability generally refers to the extent to which a system or part of a system can react adversely to an adverse event. Furthermore, the vulnerability can be understood as:

- the ability of the system and its components (elements) to accept gambling in the form of losses and damage, (Ondrasik, 2018)

- lack, weakness, or condition of the system that the threat can use to assert an undesirable condition, (Cordona, 2011)

- susceptibility to damage, (Cordona, 2011)

- the degree of the environment's ability to withstand events of a certain nature, considering the level of threat, exposure, preparedness, and preventive measures. (Gallina et al, 2016)

Based on the risk exposure differentiation, vulnerability can be divided into two aspects:

- intrinsic vulnerability - elements that can withstand, manage, and deal with risk, 
- external vulnerability - these are elements that will be exposed to and affected by the risk. (Bohle, 2001)

The vulnerability may be understood as the property of any object, technical device, or social entity to lose the ability to perform its natural or specified function due to internal/external threats, which may be different and intensity. Vulnerability represents those parts of the assessed object that do not provide the required level of protection, that is, a weak or easily overcome element in the protection system, or create suitable conditions for attacking the object, increase the probability of attack and consequently the stretch. Vulnerability studies shall include vulnerability analyzes which may include:

- identification of potential vulnerability of $\mathrm{Cl}$ objects to identified threats,

- identification of existing protective measures, and their effectiveness in reducing or eliminating the negative impact of identified threats,

- assessment of the vulnerability of the analyzed sectors. (Hofreiter 2014)

Based on their research, the authors concluded that the vulnerability of infrastructure objects depends on exposure, sensitivity, and ability to manage the possible negative consequences of impacts. In terms of exposure, we examine the duration of exposure. In terms of sensitivity, we examine how much the object is susceptible to damage caused by the threat. As part of our ability to deal with possible impacts, we look at how much we can withstand the current threat. (Hofreiter, 2004)

\section{COMPARISON OF RESILIENCE AND VULNERABILITY}

Both concepts deal with the response of systems to adverse events. Resilience understands adverse events as the ability to learn about change and develop the ability to adapt to such changes, while vulnerability seeks to block such changes. (Miller, 2010)

In another aspect of resilience, the opposite term to the term vulnerability is not considered. He considers the term resilience to be one part of the three vulnerability indicators. Other indicators are risk exposure and sensitivity. It follows logically that, although the resilience may be high, if both exposure and sensitivity are high, the system is considered to be vulnerable. (Miller, 2010)

The indicators for assessing the vulnerability of an object, its zones, and premises are:

- the degree of vulnerability, assessed by qualitative methods (expert assessments) as a small, medium, and large, and the like.

- the probability of a successful attack, which can be expressed using probability models on a scale or as a subjective probability.

Opposite indicators to the previous are:

- the degree of resilience of the object protection system (zone, building, space), where the expression of the degree of resilience will be inverse to the degree of vulnerability, i.e. if the level of a vulnerability is small, the degree of resilience will be large;

- likelihood of detention intercepted before reaching access to a protected object or the protected areas and areas of the object. (Hofreiter 2014)

Some authors present the view that while increasing the system's resilience while reducing the vulnerability of the system. That assertion also applies the other way round.

It is especially important to know the value of the protected object. If it is an object of incalculable value (cultural heritage) then the interest of the potential perpetrator will be great. It always depends on the location where the object is located, increasing the vulnerability is supported by quality physical, electronic, and sheath protection. (Kmet, \& Dvorak, 2020)

Practical Union seeks to find solutions to global problems related to climate deterioration and persistent poverty. It uses the V2R framework to find solutions. This framework addresses the examination from vulnerability to resilience. It is a framework for analysis and action to reduce vulnerability and strengthen the resilience of individuals, households, and communities. The framework sets out the key factors that contribute to peoples' vulnerability: exposure to hazards and stresses; fragile livelihoods; future uncertainty; and weak governance. It provides detailed explanations of the linkages between these factors, as well as ideas for action to strengthen resilience. 
The V2R framework has been written with the needs and interests of the Practical Action program staff in mind. However, the issues and principles in the document are also relevant to a much wider audience including practitioners, researchers, and policymakers working in livelihoods, disaster management, and climate change adaptation. It is intended to guide the reader, rather than dictate a set way of doing things. The material can also be adapted to suit communication with other audiences such as community-based organizations. (Pasteur, 2011)

The intersection of common and different properties of resistance and vulnerability assessments is shown in Figure 4.

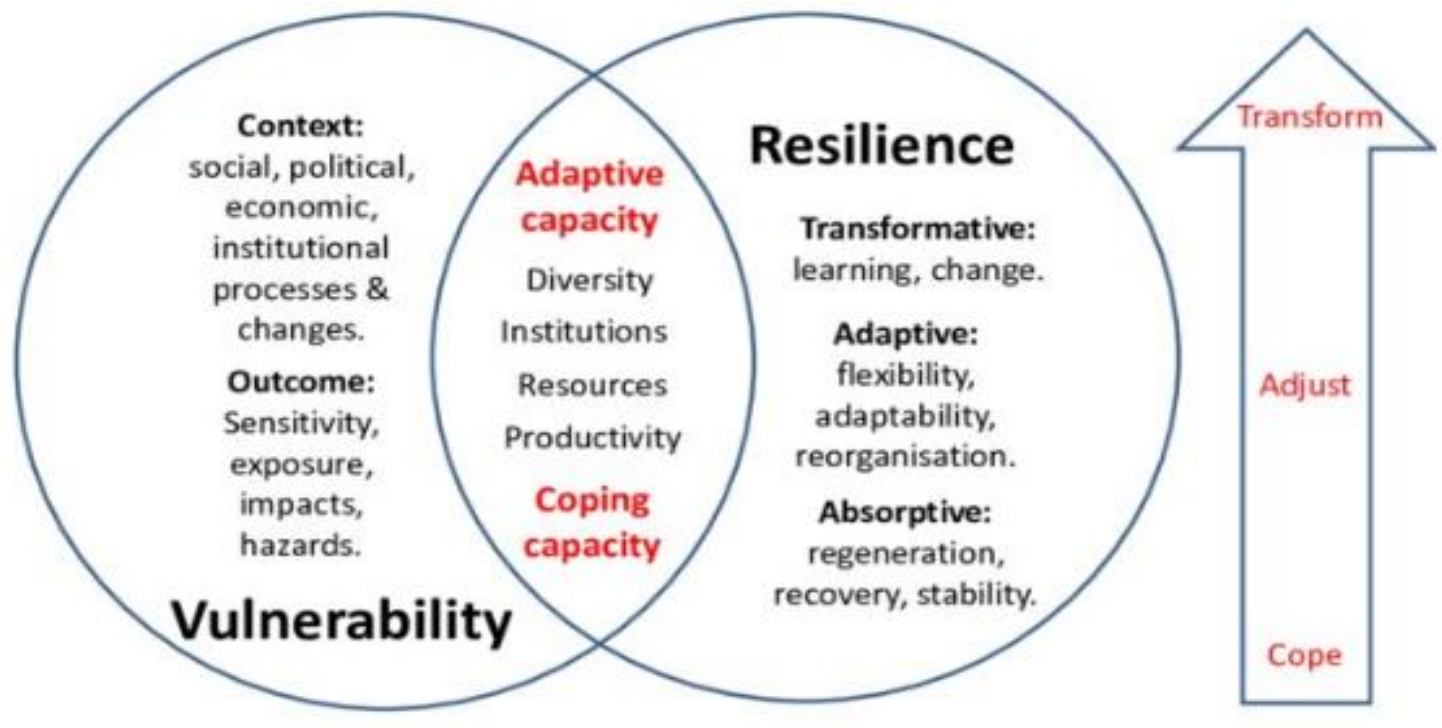

Figure 4 Penetration of resilience and vulnerability

Adaptation

\section{CONCLUSIONS}

Research on systems resilience and vulnerability is one of the important challenges in all areas of social development. Critical infrastructure protection is one of the top security issues in developed countries. Researchers at the University of Žilina have been involved in research on railway infrastructure for a long time. Current research focuses on the impact of the failure of critical infrastructure systems on the social vulnerability of the region and society.

We consider the development and testing of indicators addressing the full breadth of security as key in our research, such as:

- resilience indicators,

- adaptability indicators,

- robustness indicators,

- recovery indicators,
- vulnerability indicators,

- crime indicators,

- accident indicators,

- physical security indicators,

- fire safety indicators,

- environmental safety indicators,

- process/operational safety indicators,

- occupational health and safety indicators,

- information security indicators.

The article aimed to present the actual results of the research carried out at the Faculty of Security Engineering in Žilina. The final summary is that security needs to be examined at all levels, from personal, through corporate, local, regional, national, international to global. It is crucial to know that security research is always a multidisciplinary topic that needs to be addressed in terms of both natural, technical, social, medical, humanities, and environmental sciences. 


\section{WORKS CITED}

Act 45, 2011 about critical infrastructure. Bratislava, Slovakia: National Council.

Bohle, H.G., (2001). Vulnerability and Criticality: Perspectives from Social Geography. IHDPUpdate 2/2001, Newsletter of the International Human Dimensions Programme on Global Environmental Change, pp. 1-7.

Cordona, O.D., \& Carreno, M. L. (2011). Updating the Indicators of Disaster Risk and Risk Management for the Americas. Journal of Integrated Disaster Risk Management, 1(1), pp. 27 - 47. ISSN: 2185-8322. doi:10.5595/idrim.2011.0014

Dixon, J. L., Stringer, L. C., \& Challinor A.J. (2014). Farming System Evolution and Adaptive Capacity: Insights of Adaption Support. Resources 2014, 3, 182-214; doi:10.3390/resources3010182.

Dvorak, Z., Leitner, B., \& Rehak, D. (2019, Jul 15). Critical Infrastructure Protection Specifications in the Transport Sector. (Z. Cekerevac, Ed.) MEST Journal, 7(2), pp. 31-40. doi:10.12709/mest.07.07.02.04.

Dvorak, Z., Luskova, M. \& Cekerevac, Z. (2014). Risk reduction in critical road infrastructure in central Europe, WMSCI, Florida, USA, 2014, pp 234-239.

Dvorak, Z., Sventkova, E., Rehak, D. \& Cekerevac, Z. (2017). Assessment of Critical Infrastructure Elements in Transport, Procedia Engineering Volume 187, 2017, pp 548-555, Transportation Science and Technology: Proceedings of the 10th International Scientific Conference, TRANSBALTICA 2017; Code 128230.

Gallina, V., Torresan, S., Critto, A., Sperotto, A., Glade, T., \& Marcomini, A. (2016). A review of multirisk methodologies for natural hazards: Consequences and challenges for a climate change impact assessment. Journal of Environmental Management 168, pp. $123-132$.

Hofreiter, L. (2004). Security, security risks, and threats. First edition. Zilina: EDIS, pp. $99-106$. ISBN 80- 8070-181-4.

Hofreiter, L. (2014). Risk assessment in the protection of critical infrastructure objects. Trilobit, scientific journal, (1). ISSN 1804-1795.

Hollnagel, E. (2011). RAG- the Resilience Analysis. Resilience engineering in practice - A guidebook. Aldershot, UK: Ashgate. pp. 275-296.

Hoterova, K. (2019). Proposal of objective criteria for determining critical infrastructure elements in the rail transport sub-sector, Svet dopravy: scientific online magazine. ISSN 1338-9629 (online). No. 1 (2019), pp. 34-42.

Hoterova, K. Dvorak, Z. \& Blaho, P. (2019). Objectification of Criteria for a Critical Infrastructure Elements in the Rail Transport Sub-sector, Transportation Research Procedia, Volume 40, 2019, pp 1349-1355, 13th International Scientific Conference on Sustainable, Modern and Safe Transport, TRANSCOM 2019; Code 150446.

Kmet, R., \& Dvorak, Z. (2020, January 15). Crime index as one of the main indicators of safety. (Z. Cekerevac, Ed.) MEST Journal, 8(1), 57-64. doi:10.12709/mest.08.08.01.07.

Linkov, I., Eisenberg, D., Bates, M., Chang, D., Convertinp, M., Allen, J., Flynn, S., \& Seager, T. (2013). Measurable resilience for actionable policy, Environmental Science and Technology, Volume 47. pp. 10108-10110.

Miller, F., Osbahr, H., Boyd, E., Thomalla, F., Bharwani, S., Ziervogel, G., Walker, B., Birkmann, J., Van der Leeuw, S., Rockström, J., Hinkel. J., Downing, T., Folke, C., \& Nelson, D. (2010). Resilience and vulnerability: complementary or conflicting concepts?. Ecology and Society, 15(3): 11.

Moench, M. (2009). Adapting to Climate Change and the Risks associated with Other Natural Hazards: Methods for Moving from Concepts to Action. The Earthscan Reader on Adaptation to Climate Change, Earthscan, London, s. 249-280. 
Ondrasik, R. (2018). Geohazardy z hladiskastavebnej cinnosti. Aktualne problemy geologie : Inovacia odborno-predmetovych kompetencii. Bratislava: Iris. p. 178-189.

Pasteur, K. (2011). From Vulnerability to Resilience. Practical Action Publishing. 128 p. ISBN 978-185339-718-9.

Rehak, D.; Senovsky, P.; Hromada, M.; Pidhaniuk, L.; Dvorak, Z.; Lovecek, T.; Ristvej, J.; Leitner, B.; Sventekova, E.; \& Maris, L. (2018). Methodology of the Critical Infrastructure Elements Resilience Assessment. Ostrava: VŠB - Technicka Univerzita Ostrava, 109 p.

Rehak, D., Hromada, M., \& Novotny, P. (2016). European Critical Infrastructure Risk and Safety Management: Directive implementation in practice. Chemical Engineering Transactions, 48, 943-948. ISBN 978-88-95608-39-6. ISSN 2283-9216. DOI: 10.3303/CET1648158.

Sousek, R. \& Dvorak, Z. (2013). Methods for processing type threats in railway transport, Transport Means - Proceedings of the International Conference, pp. 278-281, Code 102486.

\section{ACKNOWLEDGMENTS}

Publication of this paper was supported by project VEGA 1/0159/19 - Assessment of the resilience level of the key elements of the ground transport infrastructure.

Received for publication:

Revision received:

Accepted for publication:
28.02.2020

28.04.2020

01.07.2020

\section{How to cite this article?}

Style - APA Sixth Edition:

Hoterova, K. (2020, July 15). Comparative analysis of the resilience and vulnerability of the railway infrastructure. (Z. Cekerevac, Ed.) MEST Journal, 8(2), 100-106. doi:10.12709/mest.08.08.02.10

Style - Chicago Sixteenth Edition:

Hoterova, Katarina. 2020. "Comparative analysis of the resilience and vulnerability of the railway infrastructure." Edited by Zoran Cekerevac. MEST Journal (MESTE) 8 (2): 100-106. doi:10.12709/mest.08.08.02.10.

Style - GOST Name Sort:

Hoterova Katarina Comparative analysis of the resilience and vulnerability of the railway infrastructure [Journal] // MEST Journal / ed. Cekerevac Zoran. - Belgrade - Toronto : MESTE, July 15, 2020. - 2 : Vol. 8. - pp. 100-106.

Style - Harvard Anglia:

Hoterova, K., 2020. Comparative analysis of the resilience and vulnerability of the railway infrastructure. MEST Journal, 15 July, 8(2), pp. 100-106.

Style - ISO 690 Numerical Reference:

Comparative analysis of the resilience and vulnerability of the railway infrastructure. Hoterova, Katarina. [ed.] Zoran Cekerevac. 2, Belgrade - Toronto : MESTE, July 15, 2020, MEST Journal, Vol. 8, pp. 100-106. 